\title{
Knowledge exchange: a review and research agenda for environmental management
}

IOAN FAZEY ${ }^{1 *}$, ANNA C. EVELY ${ }^{1}$, MARK S. REED $^{2}$, LINDSAY C. STRINGER $^{3}$, JOANNEKE KRUIJSEN ${ }^{4}$, PIRAN C. L. WHITE ${ }^{5}$, ANDREW NEWSHAM $^{6}$, LIXIAN JIN ${ }^{7}$, MARTIN CORTAZZI ${ }^{8}$, JEREMY PHILLIPSON ${ }^{9}$, KIRSTY BLACKSTOCK ${ }^{10}$, NOEL ENTWISTLE ${ }^{11}$, WILLIAM SHEATE ${ }^{12}$, FIONA ARMSTRONG ${ }^{13}$, CHRIS BLACKMORE ${ }^{14}$, JOHN FAZEY ${ }^{15}$, JULIE INGRAM ${ }^{16}$, JON GREGSON ${ }^{17}$, PHILIP LOWE ${ }^{9}$, SARAH MORTON $^{11}$ AND CHRIS TREVITT ${ }^{18}$

${ }^{1}$ School of Geography and Geosciences, North Street, University of St Andrems, St Andrems, Fife KY16 9AL, UK, ${ }^{2}$ Aberdeen Centre for Environment and Sustainability, Geography and Environment, School of Geosciences, University of Aberdeen, Elphinstone Road, Aberdeen AB24 $3 U F, U K,{ }^{3}$ Sustainability Research Institute, School of Earth and Environment, University of Leeds, Leeds LS2 97T, UK, ${ }^{4}$ Robert Gordon University, Schoolhill, Aberdeen AB10 1FR, UK, ${ }^{5}$ Environment Department, University of York, Heslington, York YO10 5DD, UK, ${ }^{6}$ Climate Change Team, Institute of Development Studies, University of Sussex, Falmer BN1 9RE, UK, ${ }^{7}$ De Montfort University, Faculty of Health and Life Sciences, Hawthorn Building, The Gatemay, Leicester LE1 9BH, UK, ${ }^{8}$ The Centre for Applied Linguistics, S1.74, Social Studies Building, University of Warmick, Coventry CV4 7AL, UK, ${ }^{9}$ Rural Economy and Land Use Programme (RELU), Centre for Rural Economy, School of Agriculture, Food and Rural Development, University of Nemcastle, Nemcastle Upon Tyne NE1 7RU, UK, ${ }^{10}$ Social, Economic and Geographical Sciences, The James Hutton Institute, Craigiebuckler, Aberdeen AB15 8QH, UK, ${ }^{11}$ University of Edinburgh, Old College, South Bridge Edinburgh EH8 9 Y L, UK, ${ }^{12}$ Imperial College London, South Kensington Campus, London SW7 2AZ, UK, ${ }^{13}$ Economic and Social Research Council, Polaris House, North Star Avenue, Swindon SN2 1UF, UK, ${ }^{14}$ The Open University, Department of Communication and Systems, Faculty of Mathematics, Computing and Technology, The Open University, Walton Hall MK7 6AA, UK, ${ }^{15}$ Ty'n Y Caeau Consultants, Tregarth, Bangor, Gmynedd LL57 4BD, UK, ${ }^{16}$ University of Gloucestershire, The Park, Cheltenham, Gloucestershire GL50 2RH, UK, ${ }^{17}$ Institute of Development Studies, Library Road, Brighton BN1 9RE, UK, and ${ }^{18}$ CEDAM, Chancelry 10T, Ellery Crescent, The Australian National University, Canberra ACT 0200,

Australia

Date submitted: 24 March 2012; Date accepted: 9 July 2012; First published online: 24 September 2012

\section{SUMMARY}

There is increasing emphasis on the need for effective ways of sharing knowledge to enhance environmental management and sustainability. Knowledge exchange (KE) are processes that generate, share and/or use knowledge through various methods appropriate to the context, purpose, and participants involved. $\mathrm{KE}$ includes concepts such as sharing, generation, coproduction, comanagement, and brokerage of knowledge. This paper elicits the expert knowledge of academics involved in research and practice of KE from different disciplines and backgrounds to review research themes, identify gaps and questions, and develop a research agenda for furthering understanding about KE. Results include 80 research questions prefaced by a review of research themes. Key conclusions are: (1) there is a diverse range of questions relating to $\mathrm{KE}$ that require attention; (2) there is a particular need for research on understanding the process of KE and how KE can be evaluated; and (3) given the strong interdependency of research questions, an integrated approach to understanding $\mathrm{KE}$ is required. To improve understanding of KE, action research methodologies and embedding evaluation as a normal part of $\mathrm{KE}$ research and practice need to be encouraged. This will foster more adaptive approaches

\footnotetext{
*Correspondence: Dr Ioan Fazey e-mail: ioan.fazey@st-andrews.
} ac.uk to learning about $\mathrm{KE}$ and enhance effectiveness of environmental management.

Keymords: adaptive comanagement, decision-making, environmental management, evidence-based conservation, knowledge exchange, knowledge management, knowledge transfer, participation, research impact, social learning

\section{INTRODUCTION}

Knowledge, experience and learning are fundamental for effective environmental management. Irrespective of its origins, knowledge shapes decisions and implementation, while the learning that occurs through research and practice influences future action (Lee 1999; Salafsky et al. 2002; Fazey et al. 2005a). Over the last two decades there has been an acceleration of research in environmental management to guide theory and practice (Fazey et al. 2005b; Lawler et al. 2006). But accumulation of knowledge and information is not enough: the effectiveness of environmental management depends greatly on how knowledge is exchanged, with whom it is exchanged, and how it is used (Pullin \& Knight 2001; Cash et al. 2003; Francis \& Goodman 2011). The importance of knowledge exchange (KE) is increasingly being recognized as key to facilitating social, environmental and economic impact of research. This is seen in requirements for funding applications to identify potential beneficiaries and strategies and pathways to impact (Phillipson et al. 2012). Yet KE is often seen as a tool rather than a complex and dynamic process with many interpretations and uncertainties about what makes the process effective and under what circumstances. This paper 
Table 1 Some of the many terms used to describe processes of KE and implied meanings of these terms.

\begin{tabular}{|c|c|}
\hline Term & Implications \\
\hline Knowledge generation & $\begin{array}{l}\text { Implies 'new' knowledge produced as an outcome of some form of process, but does not indicate the } \\
\text { nature of the process. It does not explain whether the 'new' knowledge is discrete from or a product } \\
\text { of past knowledge and experience }\end{array}$ \\
\hline Coproduction of knowledge & $\begin{array}{l}\text { Implies a process where knowledge is or can be produced through interaction with others, possibly } \\
\text { with people with different perspectives and backgrounds, through cooperative endeavours and } \\
\text { mutual learning }\end{array}$ \\
\hline Knowledge transfer & Implies knowledge is portable, a linear direction, delivery and reception in a one-way process \\
\hline Brokerage of knowledge & $\begin{array}{l}\text { Implies disputed knowledge, deliberation between different parties, and possibly mediation through a } \\
\text { third party to resolve dispute }\end{array}$ \\
\hline Storage of knowledge & Implies knowledge is portable and can be held in a form that can be accessed when needed \\
\hline Knowledge exchange & $\begin{array}{l}\text { Implies a two- or multiple-path process with reciprocity and mutual benefits, maybe with multiple } \\
\text { learning, but not necessarily recognition of the equitable value of the different forms of knowledge } \\
\text { being exchanged }\end{array}$ \\
\hline Knowledge sharing & $\begin{array}{l}\text { Implies a similar process to exchange, but possibly with greater recognition by those involved of the } \\
\text { value of the knowledge of those with whom they are sharing }\end{array}$ \\
\hline Transformation of knowledge & Implies changing the knowing or knowers towards a different state or condition in the process \\
\hline Knowledge mobilization & $\begin{array}{l}\text { Implies eliciting or spreading knowledge to a wider range of recipients, possibly with the intent of } \\
\text { increased application of knowledge }\end{array}$ \\
\hline Knowledge translation & Implies communication using a mediated language modified for recipients \\
\hline
\end{tabular}

therefore highlights $\mathrm{KE}$ as a research topic in its own right that is highly relevant to environmental management and identifies a research agenda aimed at improving understanding of $\mathrm{KE}$.

There are many definitions of knowledge and $\mathrm{KE}$ (Bierly et al. 2000; Nonaka et al. 2000; Duchelle et al. 2009) and many different terms used to describe $\mathrm{KE}$ processes. These include knowledge sharing, generation, coproduction, comanagement; transfer, brokerage, storage, exchange, transformation, mobilization, and translation (Ward et al. 2009; Best \& Holmes 2010). Use of these terms is not arbitrary, with most involving metaphors with different underlying propositions that lead to different practices (Table 1, Lakoff \& Johnson 1980; Cortazzi \& Jin 1999). A single concept or definition is unlikely to adequately encompass all of these terms. Nevertheless, for the purposes of this paper, they are generally referred to as knowledge exchange, which we define as a process of generating, sharing, and/or using knowledge through various methods appropriate to the context, purpose, and participants involved.

There is extensive research on $\mathrm{KE}$ relevant to environmental management in a wide range of fields and disciplines, including business and organizational management (Bierly et al. 2000; Argote et al. 2003; Dwivedi et al. 2011), health studies (Graham et al. 2006; Davies et al. 2008), international development (Blaikie et al. 1997; Campbell \& Vainio-Mattila 2003; Cash et al. 2003), political science (Nutley et al. 2010), environmental science, agriculture and natural resource management (for example Reed 2008; Blackstock et al. 2011; Sanchez \& MorrisonSaunders 2011). Education, linguistics, psychology, sociology and the diffusion of innovations also provide highly relevant insights into processes relating to $\mathrm{KE}$, such as how people learn, communicate, make decisions, and form beliefs and cultures (Bloom et al. 1956; Rogers 1995; Valente 1996; Entwistle 2001; Bennett \& Bennett 2003). Despite increasing recognition of the importance of social practices, interventions, and decision-making processes to enhance $\mathrm{KE}$, environmental management has had little engagement with research on $\mathrm{KE}$ from other fields. Many aspects of $\mathrm{KE}$ are also still poorly understood, such as how KE functions in different contexts, which approaches are most effective, the kinds of skills and processes required to facilitate them (Entwistle \& Smith 2002; Dwivedi et al. 2011) and how knowledge can be best mobilized to encourage transitions towards sustainability and environment related outcomes (Cash et al. 2003).

This paper has three main aims: (1) to provide a review of existing literature from a wide range of academic disciplines on KE; (2) to identify key research questions for addressing key gaps in understanding about $\mathrm{KE}$; and (3) to define an integrated research agenda for enhancing understanding about KE. To achieve these aims academics from different disciplines and diverse backgrounds were brought together to review and develop a shared interdisciplinary understanding of the state-of-the-art of KE. This involved a number of iterative steps, including a professionally facilitated workshop. This paper describes the methodology, and then presents a review of key focal research areas and associated research questions, followed by an integrated research agenda for enhancing understanding about $\mathrm{KE}$ in environmental management.

\section{METHODS}

\section{Participant selection}

$\mathrm{KE}$ is a complex field of research that requires interdisciplinary approaches to identify meaningful research questions and research agendas. Given the challenges of working with multiple perspectives and backgrounds, a moderately sized group of 20 academic experts was chosen to explore the 
Table 2 Expertise (in addition to $\mathrm{KE}$ ) of each of the twenty participants involved in the elicitation process.

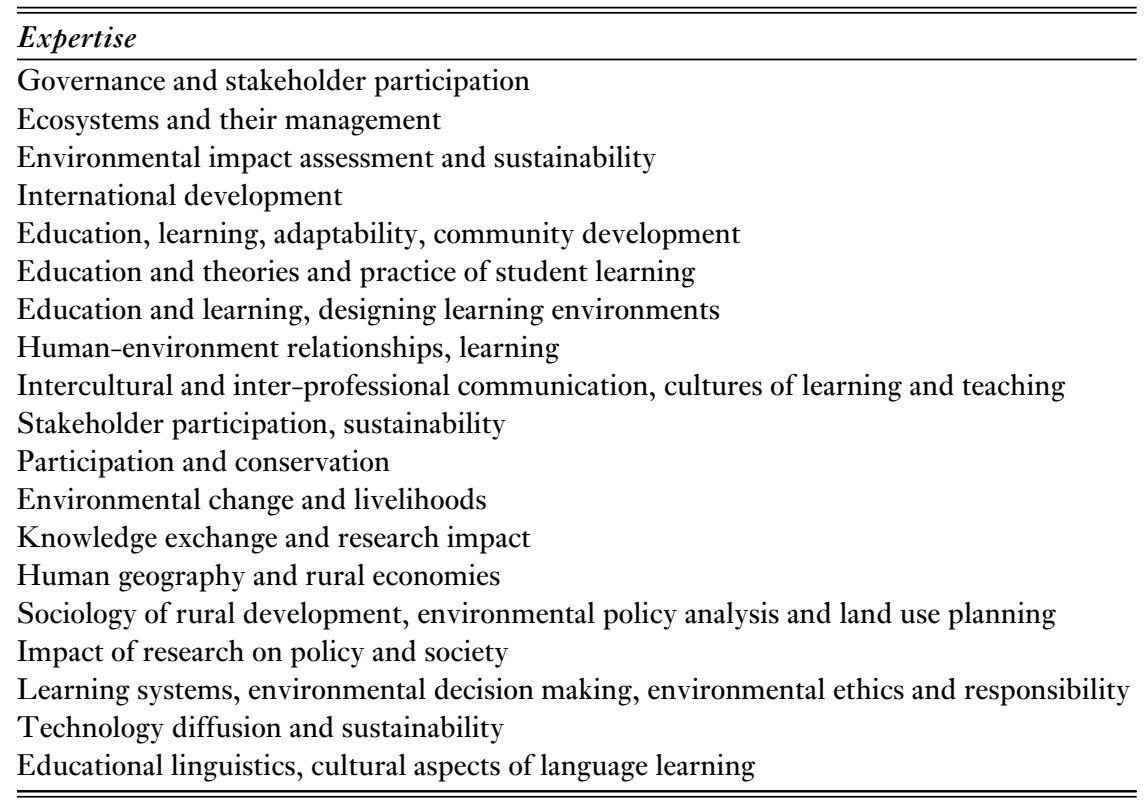

complexities of $\mathrm{KE}$, with the size of the group aiming to provide a balance of a diversity of perspectives and ability to examine in-depth a range of material. 'Expert' knowledge was chosen over 'lay' knowledge because this was an exercise to clarify and understand a complex issue (in this case KE) rather than being an exercise of public engagement aiming to make decisions about ways forward to address an issue (Fazey et al. 2006).

Many of the participants had extensive experience in the practice of $\mathrm{KE}$ and some had primary roles as $\mathrm{KE}$ professionals. Nevertheless, the primary focus was selecting participants with academic expertise for three key reasons. First, there has been no comprehensive overview of research requirements and gaps in the academic literature on $\mathrm{KE}$, and academic expertise was considered to be the most relevant to addressing this issue. Second, it was important to take a conceptual and strategic standpoint, where broad questions across disciplines and application areas were defined rather than identifying research questions for a specific context, location or management issue to which practice-based expertise would have been appropriate. Finally, the approach needed to be manageable and balance interdisciplinary breadth versus depth of investigation. The approach was therefore bounded around academic expertise to ensure that a meaningful research agenda could be developed.

The 20 participants involved in this study were identified through a review of published literature which discussed different concepts about and research on KE (Evely et al. 2012). Selection criteria for participants were: (1) that they needed to be directly involved in research and practice of $\mathrm{KE}$; and (2) have a minimum of 10 years of experience in their respective fields, which is approximately the amount of time it takes to develop characteristics typically displayed by an expert (Bransford et al. 2000). The initial literature review identified around 30 potential participants. Final decisions about inclusion were therefore also based on ensuring a breadth of expertise, mix of career seniority and gender, the capacity of individuals to be able to work in an interdisciplinary group and their availability (Table 2). All participants are coauthors of this paper.

\section{Eliciting expertise}

In general, the methodology built on other approaches used for setting research agendas in other fields of research (see for example Hoffman 1998; Steffen et al. 2004). An iterative process using ideas from Delphi methodologies (Glass et al. 2012) was used to elicit the expertise of participants. This process ensured sufficient exploration of the complexities, nuances and varied perspectives of $\mathrm{KE}$ before research questions were identified. 'Cold calling' approaches (for example, using questionnaires rather than face to face dialogue and discussion) were unlikely to have provided sufficient context, background, and opportunities for participants to explore the many issues involved.

The methodology included a number of steps (Table 3). First, two iterative rounds of preparatory questionnaires were sent to participants prior to a two-day workshop with the aim of helping them articulate their implicit expertise and to position their own perspectives in relation to that of others. Participants were then well prepared for engaging in interdisciplinary discussions during the next stage, which consisted of a two-day workshop led by professional facilitators. In this workshop participants outlined their current thinking about KE, explored concepts and shared their experiences of $\mathrm{KE}$ in various exercises, including a range of commonly used participatory techniques, supplemented with the use of rich pictures from soft systems modeling (Checkland 1998). These exercises aimed to help participants explore in-depth what they understood KE to be and the limits to knowledge about how $\mathrm{KE}$ works in 
Table 3 Key stages of the research to elicit expertise and develop the research agenda.

\begin{tabular}{|c|c|c|}
\hline Stage & Aim & Details \\
\hline $\begin{array}{l}\text { Preliminary questionnaire: } \\
\text { Round } 1\end{array}$ & $\begin{array}{l}\text { To help participants articulate } \\
\text { their implicit expertise } \\
\text { about KE }\end{array}$ & $\begin{array}{l}\text { Participants respond to a questionnaire that asked: } \\
\text { 1. How would you define knowledge? } \\
\text { 2. In what way do you think new knowledge is generated? } \\
\text { 3. What do you think characterizes a knowledge exchange process? } \\
\text { 4. What are the key questions needed to address to improve understanding of } \\
\text { how knowledge flows between people and organizations and how this flow } \\
\text { of knowledge can be enhanced? }\end{array}$ \\
\hline $\begin{array}{l}\text { Preliminary questionnaire: } \\
\text { Round } 2\end{array}$ & $\begin{array}{l}\text { To enable participants to } \\
\text { position their own } \\
\text { understanding of } \mathrm{KE} \text { in } \\
\text { relation to that of others }\end{array}$ & $\begin{array}{l}\text { Participants respond to a questionnaire with questions about the extent to } \\
\text { which they agree or disagree (and why) with responses from others to } \\
\text { questions from the first round. Both sets of preliminary questionnaires } \\
\text { meant that participants were prepared for interdisciplinary dialogue prior to } \\
\text { the next phase, and provided background to those designing the workshop }\end{array}$ \\
\hline Workshop: Initial stages & $\begin{array}{l}\text { Outline current thinking of } \\
\text { participants about their } \\
\text { understanding of KE }\end{array}$ & $\begin{array}{l}\text { Participants explored the following questions: } \\
\text { 1. What do you 'think' you know about knowledge exchange? } \\
\text { 2. What don't you know about knowledge exchange? } \\
\text { 3. What are the current thinking, models and concepts in knowledge } \\
\text { exchange? } \\
\text { 4. How do you think knowledge is held within a community of practice? } \\
\text { 5. What do you think enhances learning and absorbing knowledge? } \\
\text { 6. What do you think inhibits learning and knowledge exchange? }\end{array}$ \\
\hline Workshop: Middle stages & $\begin{array}{l}\text { Various exercises to get } \\
\text { participants to think and } \\
\text { reflect on how they } \\
\text { understood KE and what } \\
\text { was generally known about } \\
\text { KE in different academic } \\
\text { fields of research }\end{array}$ & $\begin{array}{l}\text { For example, exercises using 'rich pictures' methods (see Sorensen et al. } \\
2010 \text { ) to identify what individuals had learnt about KE from involvement in } \\
\text { past projects and group based exercises to build on this to design } \\
\text { conceptual models of KE }\end{array}$ \\
\hline Workshop: Final stages & $\begin{array}{l}\text { To identify research questions } \\
\text { and key themes }\end{array}$ & $\begin{array}{l}\text { Participants wrote research questions on post-its. These were organized into } \\
\text { groups/themes and discussed }\end{array}$ \\
\hline $\begin{array}{l}\text { Iterations to refine } \\
\text { research questions }\end{array}$ & Refine research questions & $\begin{array}{l}\text { Research questions and themes arising from the workshop were redrafted } \\
\text { (e.g. to improve clarity or remove duplicates) and sent out for two iterations } \\
\text { of comments by e-mail to all participants }\end{array}$ \\
\hline Literature review & $\begin{array}{l}\text { To provide background to } \\
\text { different themes in which } \\
\text { the research questions were } \\
\text { presented and outline } \\
\text { current knowledge about } \\
\text { the theme }\end{array}$ & $\begin{array}{l}\text { Participants who had the most appropriate expertise wrote introductory } \\
\text { sections to the different themed research questions. This was directed and } \\
\text { refined by the primary author based on the key gaps and other information } \\
\text { provided by the workshop data. The range of topics identified through the } \\
\text { research questions meant that not all material could be reviewed in-depth } \\
\text { (each would have been a separate research paper). The literature review } \\
\text { therefore provides a general overview of the theme, with selection of } \\
\text { material that was included being decided by the primary author of that } \\
\text { section with comments provided by other authors }\end{array}$ \\
\hline Coding research questions & $\begin{array}{l}\text { To develop an integrated } \\
\text { research agenda }\end{array}$ & $\begin{array}{l}\text { Research questions were coded into subtopics of key parts of the KE process } \\
\text { and broader themes. These were then discussed and agreed and resulted in } \\
\text { the integrated research agenda }\end{array}$ \\
\hline
\end{tabular}

order to provide background thinking before they identified the research questions. The exercises were also designed to elicit information to address aims that were beyond the scope of this paper (for example, to produce a conceptual model of $\mathrm{KE}$ ). During the workshop, results from exercises were collated in different ways, such as through direct writing of information by participants on sheets/post-its, through written short reports, or diagrams/schemes.

Towards the end of the workshop, participants were asked to identify key research questions. These were sorted into themes. The list was refined and finalized by participants in two additional iterations by e-mail. Participants then contributed to writing short reviews of each theme under direction of the primary author. The themes to be reviewed emerged inductively from the questions, but the literature reviewed was influenced by the expertise of those who contributed to different sections, with moderation and direction by the primary author to ensure that it focused on the key issues that emerged from the workshop. The literature presented in this paper is therefore a guide or preface to the themes rather than specifically a 'result' of the process. Finally, to develop a more specific research agenda for $\mathrm{KE}$, the research questions were coded into subtopics and in relation to four different stages of a KE process and to two additional broader 
themes. The end result was a list of specific sub-topics of research under six focal research areas.

\section{RESULTS}

\section{Experts' perspectives of what constitutes KE}

It was clear during the workshop that the way participants perceived knowledge and $\mathrm{KE}$ influenced the kinds of research questions elicited. It is therefore helpful to understand the general ways participants conceptualized and framed KE. Participants' perspectives about KE highlighted the multi-faceted nature of $\mathrm{KE}$ with a diverse range of social process, contextual influences and challenges to effective implementation. Despite different views about some of the details, there was considerable general agreement about what it involved. Conceptualizations were similar to how KE was often defined in the literature (for example Bierly et al. 2000; Nonaka et al. 2000) with participants' responses to the questions in the initial stages of the workshop often expressing the following:

- $\mathrm{KE}$ is generally a process of individual or social learning within or between groups of individuals;

- the process of $\mathrm{KE}$ can be unidirectional, but to be more effective, KE needs to be seen to be a multidirectional process that involves the coproduction of knowledge;

- viewing knowledge as something that can be passed around in inert form through traditional processes of 'transfer' is outmoded and does not reflect what is known about how knowledge is constructed and shared;

- viewing knowledge as fixed or inert, no matter who exchanges it, how it is exchanged, or in whichever context is problematic. Such a view does not reflect relatively common and accepted understandings of researchers on knowledge about how it is constructed and shared;

- $\mathrm{KE}$ is very significantly influenced by a range of contextual factors including political and social considerations, power relationships, the status of individuals, and what the process aims to achieve;

- outcomes of $\mathrm{KE}$ can be wide ranging, from the generation of information that can be shared, individual learning, enhanced cohesion and trust, empowerment, participation, ownership and responsibility for decision-making, and flattening of hierarchies between individuals and groups;

- outcomes depend on a range of individual factors, such as how people internalize knowledge, the skills of facilitators of KE, and past experience, expertise and background; and

- outcomes depend greatly on how KE is defined, how goals are identified, and projects implemented.

\section{Key research themes and questions}

Participants identified a wide range of research questions and themes (Table 4). We reviewed each research theme's relationship to the associated research questions.

\section{Defining and conceptualizing $K E$}

There is a multitude of definitions, perspectives, concepts and models of knowledge and how people acquire knowledge (Bierly et al. 2000; Hofer 2000; Nonaka et al. 2000; Evely et al. 2008; Trevitt 2008; Evely et al. 2012)). Such perspectives have profound impacts on a whole range of individuals' activities, such as reasoning, perspectives on what counts as evidence, how people relate to and manage complex problems, and their capacities for learning (Hofer 2000; Fazey 2010). Importantly, how people perceive or define 'knowledge' also influences how KE processes are designed and implemented (Evely et al. 2012). Understanding the relationship between such perspectives and their implications for effective implementation of $\mathrm{KE}$ is therefore important.

For example, viewing knowledge as something explicit that can be passed between people tends to result in traditional processes of dissemination where the 'facts' are communicated to different groups. 'Transmissive' perspectives of knowledge tend to maintain the existing status of those involved (for example external conservation expert versus indigenous knowledge) and fails to recognize the complexities of the learning processes in knowledge sharing (such as how cultural background influences what is understood, learnt and shared). At the other extreme, viewing knowledge as a more complex, iterative process of reflection, experiential learning, making implicit knowledge explicit and internalizing the results of a process of sharing knowledge with others, tends to lead to approaches that emphasize the coproduction of knowledge and more adaptive forms of learning (see for example Armitage et al. 2008; Sheate \& Partidário 2010). Such approaches recognize the existence of multiple perspectives and different forms of knowledge, and require continuous attempts to learn from and understand others; these approaches are more likely to lead to adaptive forms of environmental management and longer lasting or more effective outcomes (Reed 2008; Evely et al. 2012). Therefore, while all models of knowledge and $\mathrm{KE}$ will be useful in some contexts, important questions about how perspectives of knowledge and $\mathrm{KE}$ influence the process and outcomes of $\mathrm{KE}$ and environmental management remain (Questions 1-7, Table 4).

\section{Evaluating $K E$}

Environmental research and practice almost always involves some form of exchange of knowledge or information, whether this is a presentation at a conference or more sophisticated and extensive processes of community engagement and decisionmaking. Whatever the form of $\mathrm{KE}$, specific approaches are usually employed to achieve specific outcomes. For example, the Wensum Alliance, a catchment management programme in the UK (http://www.wensumalliance.org.uk/), aimed to reduce impacts of agricultural diffuse water pollution on ecosystem function while maintaining food security. Multiple on-farm measures were implemented across whole river catchments using local expertise to solve local problems. A key aspect of the work aimed to engage the wider public, and thus open day events were used as an approach to 
Table 4 Key research questions about KE identified by the experts.

Defining and conceptualizing $K E$

1. How are definitions of KE influenced by, and related to, definitions of knowledge and processes of knowledge generation, co-generation, storage, transfer and management?

2. Which academic theories or models are useful for what kinds of practice of KE?

3. How do individuals' theoretical starting points affect their definition of KE?

4. Is it possible to have a general theory, model or mechanism for $\mathrm{KE}$ or are these always context specific?

5. What are the main fields of study that can provide insights into improving effectiveness of KE, and how can this knowledge be applied in different contexts (e.g. How can KE in environmental management be transferred to community development)?

6. What are the main theoretical points of agreement and disagreement around KE?

7. Given that $\mathrm{KE}$ is often context dependent, is it possible and/or useful to develop generalized good practice guidelines for KE?

Evaluating $K E$

8. What indicates success in a KE process?

9. How can the use of shared language in $\mathrm{KE}$ processes be encouraged?

10. What are the possible outcomes from $\mathrm{KE}$ at individual and collective levels?

11. In what way is KE ultimately about the impact the process delivers or about learning and changing attitudes/mind-sets?

12. What sorts of outcomes do different types of participants typically want from KE processes?

13. What are the most appropriate time-horizons over which to evaluate or study KE processes?

14. What criteria should be used to evaluate the success of KE processes in different contexts and over different time-horizons?

15. What are the challenges of developing universal evaluation criteria?

16. If a sub-set of universal evaluation criteria can be identified, what would they be?

17. What forms of KE processes (e.g. one-way knowledge transfer or co-generation of knowledge) work best for different decision-making processes in different contexts?

18. How can people track the ways in which knowledge is transformed through KE processes?

19. What kind of processes results in long-lasting effects?

20. What enhances institutional memory and ensures that knowledge is not lost or held in a latent form?

Efficiency and effectiveness of $K E$

21. What factors influence the effectiveness of KE?

22. What barriers (personal, institutional, market, policy and regulatory barriers) currently exist to participation in KE and how can these be overcome to engage a wider range of participants?

23. What role does trust play in improving the effectiveness of KE processes?

24. How can the development of relationships to enable more effective KE between different types of participants in different contexts be facilitated?

25. What factors influence participants' feelings of satisfaction in $\mathrm{KE}$ and how does this relate to perceptions of identity in environmental management and engagement over the long-term?

26. What role do different forms of social interaction play in $\mathrm{KE}$ in different contexts, e.g. different types of face-to-face interactions (e.g. workshops, collective action) versus virtual interactions (e.g. social media platforms, online forums)?

27. In what contexts and for what purposes would non-interactive, one-way, knowledge transfer be more appropriate than more interactive or reciprocal KE processes?

28. How can it be ensured that $\mathrm{KE}$ is genuinely multi-directional and not tokenistic?

29. What incentives and conditions need to be in place for different groups of people to want to engage and remain in a KE process?

30. What are the conservation impacts of different kinds of KE processes?

31. To what extent does the transformation of knowledge during KE processes facilitate (e.g. by adapting knowledge to specific contexts) or hinder (e.g. by introducing errors) the extent to which KE processes meet their stated goals?

Profiles of people involved in KE

32. How do different epistemologies (ways of viewing and constructing knowledge) and ontologies (values/beliefs) influence the flow and transformation of knowledge through peer-to-peer networks?

33. How can KE processes overcome different worldviews of different communities of practice?

34. What is the role of 'experts' versus 'lay people' in KE?

35. How do different motivations of individuals influence KE (e.g. 'altruism' versus 'what's in it for me?')?

36. How does engagement and benefit of KE differ according to age, gender, ethnicity, class and other social-economic characteristics?

37. How can KE processes be designed to include a diversity of people, perspectives and contexts?

38. How do conceptions and impact of cultural context differ for KE processes?

39. How are cultural perceptions of the environment and conservation relevant to KE?

40. How do cultures of learning affect interaction and transactional practices in KE?

41. How might the choice of a language in multilingual contexts, or the use of interpreters and translators, affect KE processes and outcomes?

42. What can be learnt by studying processes that emerge from practitioners outside of formal research contexts?

43. How do different kinds of people integrate knowledge from external sources with their personal experiential or tacit knowledge? 
Table 4 (Continued)

Expertise and skills for $K E$

44. What are the skills and thinking dispositions of expert knowledge brokers that underpin effective KE?

45. By what 'processes' do individuals become 'more expert' in KE settings?

46. How can key gatekeepers and knowledge brokers be identified and enabled to spread ideas more widely?

47. What skills are needed to design and manage an effective KE process?

48. To what extent do knowledge brokers need in-depth understanding of the different cultures between which knowledge is being exchanged?

49. What incentives and professional support are needed to enhance the development of knowledge brokering skills?

50. How does brokered knowledge differ from 'new' knowledge produced by others and does it matter?

Role of power in influencing $K E$

51. How does power or status influence $\mathrm{KE}$, and how can these influences be managed more effectively?

52. Who could/should decide who is involved and whether involvement should change during a KE process?

53. How does inequitable development (e.g. in integrated conservation and development programmes) affect access of marginalized groups to KE processes?

54. Whose knowledge counts most in a given KE process, and why does this occur?

55. What are the ethical dimensions of KE?

56. How do projects use KE be a process of empowerment?

57. How do project avoid setting up exchange processes which generate knowledge that serves to reproduce marginalization?

Participation and co-production of knowledge

58. What can be learnt from the participatory and co-management, co-production literature about KE?

59. How do conventional forms of KE relate to broader approaches to societal engagement such as deliberative democracy?

60. In what contexts can public and stakeholder participation facilitate KE?

61. Who are or should be the gatekeepers of knowledge?

62. When is a knowledge broker needed?

63. What kinds of participation and co-generation of knowledge are best suited to different stakeholders, circumstances and contexts?

64. When and where is investment in trust building needed most, e.g. interaction within farmers' groups may need more trust building than different groups of academics working together.

65. What are the different kinds of institutional structures that are relevant to and affect opportunities for co-generation of knowledge?

66. How do people internalize knowledge that is co-created? (e.g. do all involved understand a process of co-creation in the same way)?

67. What types of $\mathrm{KE}$ are best suited to different issues of participation? (e.g. the processes of achieving consensus might be different from just needing to understanding a particular issues)?;

Tools and techniques for $\mathrm{KE}$

68. What trends are occurring relating to institutionalization, process design, tools and techniques of KE?

69. What role do new technologies (e.g. Web 2.0 and social media platforms) play in KE?

70. What techniques and tools are currently found to be effective in KE?

71. What techniques and tools are available to create and facilitate more joined-up data sharing?

72. When participants' world views are very different, what are the best tools to bridge them?

73. What insights are there from existing processes (e.g. research, strategic assessments) that enable more effective design of KE?

Changing context and nature of $K E$

74. What research priorities and perspectives on $\mathrm{KE}$ are held by practitioners, policy-makers, and the public?

75. How is the science-society interface relationship changing, and what are the implications for the way KE is delivered and conceptualized?

76. In the wider world how are hierarchies of expertise changing (e.g. the relation between formal/professional and scientific expertise and other sources), and what implications does this have for the design of KE processes?

77. What are the time and financial implications of increasing emphasis on KE, and how can innovative approaches be developed to reduce these costs?

78. How do incentive structures need to be different, or what kinds of incentives need to be introduced to enable researchers to engage more in effective KE?

79. How can KE keep pace with accelerating expansion of information?

80. How can research on KE be best exchanged and enhanced through adaptive mechanisms?

demonstrate progress and the inclusive nature of the alliance. In another project, research to identify trajectories of change and vulnerability in remote communities in the Solomon Islands also aimed to enhance social learning and capacity building at local levels. In this case KE was fully embedded in the research processes by using participatory methods and by explicitly designing data collection as an iterative and multiscaled mechanism that enhanced learning of researchers, local research assistants and community members (Fazey et al. 2010).

These examples highlight the increasing recognition of the need to identify desired KE outcomes and then design processes in ways that are likely to achieve them. Very few projects, however, evaluate the outcomes of $\mathrm{KE}$ and even fewer constructively align outcomes, project design and evaluation. Continual examination of what is understood or 
known is an inherent component of adaptive environmental management to deal with uncertainty (Salafsky et al. 2001; Allan \& Stankey 2009). Adaptive management requires effective $\mathrm{KE}$ mechanisms to ensure that knowledge is shared and preconceptions challenged; the KE process itself also needs to respond flexibly to new insights that may achieve more effective results. Thus evaluation of the $\mathrm{KE}$ component is also essential to achieve more effective adaptive management.

There are many different approaches to evaluation, but all generally emphasize the importance of explicitly assessing the desired outcomes of an intervention (European Communities 2006; Shufflebeam \& Shinkfield 2007). Evaluating KE, however, is particularly challenging because it is difficult to demarcate the scope and spatial/temporal boundaries of a $\mathrm{KE}$ programme and to consider the broader issues of nested and hierarchical scales of governance and organizational or political scales (Cundill et al. 2005; Marshall 2008; Phillipson et al. 2012) that generate multiple variables, objectives and outcomes. For example, there may be much longer-term legacies, such as continued development of relationships, new insights and the wider exchange of knowledge that would not have occurred without the initial KE project (Phillipson et al. 2012), and there are challenges of linking or understanding how KE processes operating at community levels influence higher levels of governance and management of common pool resources (Marshall 2008).

Evaluation is also challenging because it is difficult to define what is considered a successful outcome of KE. For example, volunteers in conservation projects with high levels of engagement, greater sharing of knowledge and involvement in making decisions learn more about conservation and working as a team than volunteers in projects who have less engagement (Evely et al. 2011). This research indicates the kinds of processes that are most effective for delivering learning among the participants of KE. But it does not reveal whether the projects with high engagement were necessarily more effective in achieving a specific conservation outcome, such as the conservation of target species, or whether learning outcomes give rise to more successful but different projects in the future. Projects therefore need to carefully consider whether their evaluations should include the intended environmental outcomes and/or other aspects that relate to the delivery of the KE process per se, such as whether the learning of participants or team cohesion are enhanced.

Some approaches to evaluation emphasize the need for participatory engagement of stakeholders in the process of setting goals and objectives and implementing the evaluations (Zukoski \& Luluquisen 2002; Fetterman \& Wandersman 2005). These participatory evaluation approaches are particularly relevant to $\mathrm{KE}$ in environmental contexts because they simultaneously enable evaluators to work with stakeholders and project managers to identify the objectives and scope of $\mathrm{KE}$ interventions, while also embedding evaluation in projects in ways that encourage adaptive comanagement (Fetterman \& Wandersman 2005).
Participatory evaluation is therefore likely to be one of the most fruitful approaches to developing $\mathrm{KE}$ evaluation methodologies. Overall, these kinds of issues raise fundamental questions over the evaluation of $\mathrm{KE}$ and its wider impact (Questions 8-20, Table 4).

\section{Efficiency and effectiveness of $K E$}

In addition to questions about the framing of evaluation of $\mathrm{KE}$, there are also important questions about what influences the effectiveness and efficiency of KE (Dobbins et al. 2009). Effectiveness relates to the extent to which the desired outcome of a process or intervention matches the actual outcome, while efficiency refers to how easily an outcome is achieved given a set of resources, such as time or funding. Thus two different approaches to KE might result in similar outcomes, and have similar effectiveness, but one of them may be less costly to deliver and therefore more efficient. In environmental management both effectiveness and efficiency are important (Laycock et al. 2009; Laycock et al. 2011). However, as indicated above, it can often be difficult to define success in KE. For example, in some circumstances, a one-day conservation conference with presentations between academics and practitioners may be sufficient to meet a desired outcome of KE, but this may miss additional benefits provided by a three-day facilitated workshop, or a series of iterative workshops, that potentially enable deeper discussion and the building of trust and relationships essential for long-term collaboration and the emergence of important new insights at a later date. A one-day conference may also be disempowering, resulting in some of those who need to be involved most becoming demotivated and disengaged.

This suggests that KE effectiveness might need to consider 'satisfaction': an insight which comes from intercultural communication research (Ting-Toomey 1999: 265). Satisfaction can be defined as the extent to which all participants develop positive feelings about the KE process and outcomes and, at a deeper level, the extent of their feelings of positive affirmation about how their desired identity is elicited or validated (namely the degree to which participants feel engaged and involved, patronized or bypassed, and how these feelings affect their perceptions of themselves and roles as environmental practitioners and researchers, or as being part of $\mathrm{KE}$ ). A reasonable level of satisfaction may mean that participants are willing to continue to share and exchange knowledge, which is vital for viable longer-term sustainability of a project.

The effectiveness and efficiency of $\mathrm{KE}$ also depend on the context in which it operates (Entwistle \& Smith 2002). It is usually easier, for example, to achieve exchange of knowledge when people are from similar backgrounds, such as researcher to researcher, compared to working with people who have very different goals, languages, pressures, needs and career paths, such as policy-makers and researchers (Choi et al. 2005). Yet if processes are well-designed, then the sharing of knowledge from more disparate backgrounds can result in much more profound transdisciplinary insights (Tress et al. 
2005). What works best will therefore usually depend on the desired outcomes of a KE project and a range of contextual factors. Many questions remain about aspects that influence the effectiveness of KE (Questions 21-31, Table 4).

\section{Profiles of people and cultures involved in KE}

A particular challenge for effective $\mathrm{KE}$ is managing the different kinds of people involved. People have different experiential and cultural backgrounds that affect their interpretation of new information (Alcorn 1993; Reid et al. 2011). Several important and often overlooked aspects are the cultural values, beliefs and practices towards the environment, processes of learning, and social interaction and language (Lansing 1991; Fischer et al. 2012). These aspects of culture affect interpretations of knowledge and its exchange in different ways. For example, perspectives of nature, environment and landscapes are usually embedded in a cultural community's heart, mind and memory. In Apache culture in Arizona, place names are linked with stories, which in turn evoke moral concepts and ideas about wisdom. For members of these communities, places are visual symbols of cultural norms and place names are used to socialize children into community values (Basso 1996). Such cultural norms can then translate into fundamentally different ways of knowing about and approaches to managing the environment (for example Lansing 1991; Berkes et al. 2003). Failing to understand or incorporate cultural senses of place can significantly hinder KE.

Culture also influences learning. This includes the cultural beliefs, values and practices regarding teaching, learning, getting and using knowledge, and how these affect interactions between learners. For example, many learners in China prioritize deep knowledge and the moral behaviour of an expert much more than most British learners. Chinese participants avoid asking or postpone questions to show respect, or wait for the knowledge to be transmitted or processed, enabling them to ask themselves more questions. British participants, however, prefer to ask questions more spontaneously and consider interactive participation to be a key part of their own on-going learning process (Cortazzi \& Jin 2002).

The cultural ways of speaking, or discourse structures of a community, also affect how knowledge is exchanged. For instance, in formal, academic or professional settings, many Chinese speakers provide substantial background of history or theory before leading up to a main point, which may be briefly expressed. This ensures common ground and that, given the background, the hearer may easily appreciate the main point, which therefore needs little elaboration and if understood can be applied by implication. Conversely, many American or British speakers prefer explanations where the main idea is briefly expressed as a signal of what is coming, then background or theory given briefly (since the main point is already known) and the main idea repeated, elaborated and applied. Because such practices lead to different expectations in listening, the main point may be missed if people are unaware of the different ways of communicating (Scollon \& Scollon 2001). Crucially, any misunderstanding of the 'content' in KE can be because of a misperception of either or both the person giving and receiving the message (Scollon \& Scollon 1981).

Finally, cultural differences are also mediated through language. In multilingual contexts where several languages are available for participants (including first, second or other languages), there may be a tendency to use English as the obvious choice of language for KE. However, language choices can affect participants' feelings about interaction and the content of discussions (Cortazzi et al. 2011). The use of interpreters and translation is also not straightforward, since this usually involves mediation between different cultures.

Overall, environmental management involves exchange of knowledge between people with different backgrounds and cultures, such as between practitioners and indigenous people or between researchers and policy makers. However, consideration is rarely given to cultural and individual differences of participants involved in KE. Many questions remain about the way different backgrounds, experience, values and perspectives affect KE (Entwistle 2001; Evely et al. 2008) (Questions 32-43, Table 4).

\section{Expertise and skills for $K E$}

$\mathrm{KE}$ is based on an assumption that expertise and knowledge, and sources of knowledge production, are distributed widely among scientists, practitioners, businesses, land managers and other stakeholders and the public (Phillipson et al. 2012). A key set of intermediaries between sources of expertise are knowledge brokers (Gould \& Fernandez 1989; Klerkx \& Leeuwis 2008; Ward et al. 2009). Knowledge brokering is undertaken by a range of organizations and individuals who absorb complex ambivalent messages from diverse sources including technical, commercial and legislative developments and translate them into terms that can be understood and acted upon (Gerrish et al. 2011; Verbeke et al. 2011). They rely heavily on social networks and links within and across institutions (Reiche et al. 2009). Within the arena of environmental management, there are many individuals who perform key roles in acting as formal knowledge brokers (Hogan 2002; Reed 2008). Recent work on farm advisors underlines the importance of understanding the expertise and skills underpinning brokerage activities (Proctor et al. 2011). Advisors act as intermediaries bringing scientific, regulatory and professional knowledge to the farm. However they are not simply conduits of knowledge. They also generate their own knowledge from their experiences in the field and their interactions with other experts, including other advisors and farmers. Knowledge is therefore not only exchanged by brokers but is also developed and modified as a result of such interaction (Meyer 2011). Effective KE is therefore not just about the brokerage of abstracted scientific knowledge generated by research; it is also about the interaction of different types of experts and, through this, the exchange of socially distributed, embodied, contextualized and skilful 
expertise (Gerrish et al. 2011). Effective brokerage also relies on target groups, such as national organizations, to optimize their capacities to absorb new knowledge (Lane \& Rogers 2011). There is therefore a need to address a range of research questions about the kinds of skills and expertise needed to encourage $\mathrm{KE}$ and how to identify key gatekeepers of knowledge in different settings (Questions 44-50, Table 4).

\section{The role of power in influencing $K E$}

Power dynamics, including the relative position or status of those generating and using knowledge, may significantly affect who has access to knowledge and how it is transformed and used in KE (Ingram \& Stern 2007; Garnett et al. 2009; Brugnach \& Ingram 2012). Status and 'positional' power or social, personal or transpersonal power can be mediated in a number of ways, such as through the activities of special interest or pressure groups; differences in formal educational status, and resources and skills, and through cultural barriers that prevent equal participation of certain (often disadvantaged) groups (Ingram \& Stern 2007; Whiteley et al. 2008). Power dynamics influence whose voices get heard in decision-making (Williams et al. 2003; Reed 2008), which is clearly important in, for example, local environmental decision-making (Partidário \& Sheate 2013). One of the most significant ways that power can influence $\mathrm{KE}$ is the power to choose who and what information is included or excluded from a KE process .

These considerations of 'who has power over whom', or the 'power to' exclude knowledges or voices from an exchange process are derived from a view where power is seen to be an aspect of the capacity to bring about or influence an outcome (Barnes 1988). However, power can also be viewed as a 'distribution of knowledge' which operates through both individual and collective action, rather than residing in any particular individual (Foucault \& Gordon 1980; Barnes 1983). This view suggests that social order is achieved because people act in accordance with accepted, shared knowledge rather than through coercion by a ruler and enforcement through an overwhelming power of personal authority. One example of this kind of power is money (Barnes 1988). Money has, strictly speaking, no empirical existence as it is simply a promise to pay the recipient the equivalent sum of money in goods. Nevertheless, shared beliefs about and common acceptance of money shapes and structures social life in fundamental ways, and facilitates countless kinds of individual and collective actions, including those relating to environmental management. 'Power' therefore comes from acceptance of beliefs about what money is and the way in which this shapes actions.

There is general acceptance in these kinds of perspectives that power is inseparable from knowledge. However, there are different views on what kind of social order results from this inseparability. Foucault's take on power as a distribution of knowledge tends to highlight negative (undesirable) instances of power operating through institutions (such as those of the state) that render people as individuals that can be subject to analysis and control (Foucault \& Gordon 1980). Foucault and Gordon (1980) did not insist that power must always operate in this way, but one of the aims of their analysis of power was to identify points of resistance to current operations of oppressive power. Others, however, suggest that power relations can have positive, as well as negative effects (Barnes 1988). For example, the inequitable distribution of money across a given society can be seen as a negative power dynamic, in normative terms. Yet, even in such a society, many forms of collective action deemed beneficial by members of that society also occur: for example, goods or payments for ecosystem services may encourage conservation outcomes if these programmes are delivered appropriately (Cranford \& Mourato 2011; Prager et al. 2012). In this view, the power of money comes from collective acceptance of it as a mechanism of exchange, rather than because certain individuals have more of it than others.

Viewing power as a distribution of knowledge has three important implications for understanding KE. First, it highlights $\mathrm{KE}$ as a process of empowerment or disempowerment, where sharing and exchanging knowledge is inseparable from the dynamics of power. Second, viewing power as a distribution of knowledge focuses attention on the need for appropriate theoretical lenses for understanding the conditions for and the workings of empowerment and disempowerment. Third, differences in the views of key thinkers, such as Foucault and Barnes, on power as the distribution of knowledge, are driven by attempts to understand why people believe what they do, rather than establishing what is 'true' or 'false' in their beliefs. This leads to approaches where no one in a $\mathrm{KE}$ process is assumed to have privileged 'true' knowledge and where knowledge claims are treated 'symmetrically' regardless of their origin or how credible they may seem (Bloor 1991; Barnes et al. 1996). This then requires processes that facilitate consensus through negotiation and inclusion and respect for the knowledge claims of all involved.

Taking on board the implications of viewing power as a distribution of knowledge, or as individuals or groups having power over others, is likely to lead to a more appropriate and carefully designed KE process. Effective facilitation and careful process design can reduce the influence of power, such as that of dominant or reticent individuals (Hogan 2002), while investigation using tools such as social network analysis, discourse analysis or participant observation can inform participant selection as a way of managing power dynamics (Reed et al. 2009). This raises a number of ethical questions about the design and implementation of KE, such as consideration of intellectual property rights, the ethical issues of including or excluding marginalized groups, and how power is used to influence what is considered by some to be 'valid' knowledge. In general, there is a wide breadth of research questions about the relationship between power and KE (Questions 51-67, Table 4).

\section{Participation and the coproduction of knowledge}

Participation is often defined as a process where stakeholders (namely individuals, groups and organizations) are actively 
involved in making decisions that affect them (Webler et al. 2001; Rowe \& Frewer 2004; Hage et al. 2010). Participatory processes typically refer to direct face-to-face contact between stakeholders, but may also include other forms of interaction, such as using social media. Most researchers argue that participation involves ensuring the knowledge and views of people are more equitably incorporated in decisions, such as using approaches that flatten hierarchies to reduce the influence of powerful individuals or groups that can skew decisions (Gaventa et al. 2004; Hickey \& Mohan 2004). As such, participation requires the management and reformation of power-relationships and the creation of spaces for empowerment (Chambers 1997; Williams et al. 2003), and is closely related to understanding how knowledge is exchanged and used. In particular, given the inseparability of knowledge and power (Foucault \& Gordon 1980; Barnes 1983), knowledge sharing, learning and participation are closely intertwined (Partidário \& Sheate 2013).

The related concepts of coproduction of knowledge and comanagement both view different forms of knowledge (such as indigenous, lay, expert or formal) as having an important role in decision-making and implementation (Raymond et al. 2010). These approaches to management emphasize the importance of codesign, analysis and evaluation in ensuring that both the outcomes of a $\mathrm{KE}$ process (for example, what is learnt or understood) and outcomes of action (such as implementation of conservation projects) are more readily accepted, reducing the potential for conflict with or disengagement of disillusioned stakeholders. Such approaches are distinctly different from the fortress approaches to environmental conservation of the past, which placed a greater emphasis on the exclusion of some groups (and thus, their knowledge) through restricted one-way processes of communication combined with top-down regulatory enforcement of rules and laws (Adams et al. 2001; Brockington 2002).

While there are many benefits to participation, such as improved and more sustained outcomes, avoidance of litigation costs, enhanced education and learning, empowerment of marginalized groups, and breaking gridlock and conflict (Irvin \& Stansbury 2004; Fetterman \& Wandersman 2005; Armitage et al. 2011; Evely et al. 2011), there are also potential challenges. These include higher financial, time and resourcing costs, potential for domination of strongly partisan groups, possibile creation of greater hostility toward governments, and decisions that can be unduly influenced by economic interests (for example when there is inadequate representation of environmental interests) (Irvin \& Stansbury 2004). Much of these challenges emerge through processes that maintain or strengthen existing power relations (Kapoor 2002; Irvin \& Stansbury 2004), and greatly depend on how participatory approaches are conceptualized and implemented rather than simply being a result of fundamental flaws in ideas about participation (Parfitt 2004).

Overall, there is much that KE practitioners and researchers can learn from participatory and coproduction processes, the role of facilitators used in participatory dialogue, and the influence of formal and informal institutional structures and cultures on processes of KE and participation (Questions 5867, Table 4).

\section{Tools and techniques for $K E$}

The way people define knowledge and $\mathrm{KE}$ processes not only determines how these processes are designed and implemented (Evely et al. 2012), but also the tools and techniques used. For example, coproduction and participation can be viewed as a specific approach to $\mathrm{KE}$ with an associated toolkit of methods (such as stakeholder identification and analysis, and facilitated deliberative workshops). A specific example has been the application of 'object world' tools, developed with insights from anthropology and semiotics, to understand and improve technology diffusion (Bucciarelli 1988; Kruijsen 1999). These tools recognize the importance of seeing through the different backgrounds of stakeholders created by factors such as education, upbringing and culture, to improve the understanding of participants' perceptions and motivations. Such tools would, for example, be useful in discussions to develop nature conservation strategies between stakeholders that perceive nature as 'a park' (who are more likely to choose a 'strict taking care' interventionist type of strategy) and those perceiving nature as 'untouched wildlife' (who would support a 'do not interfere' or more laissez-faire strategy).

Tools for analysis of perceptions are only a small part of a wide range of techniques available to $\mathrm{KE}$ practitioners and researchers (Cribb \& Hartomom 2002; Hogan 2002; Sheate \& Partidário 2010). There are also many mechanisms that may not initially be considered to be a specific tool for $\mathrm{KE}$, but can be used to enhance it. This includes participatory and deliberative research methods (Chambers 1997). For example, deliberative approaches to environmental valuation using choice experiments can enhance $\mathrm{KE}$ and learning while also increasing the validity of the results (Kenter et al. 2011). Similarly, strategic assessments (for example vulnerability or environmental impact) where KE takes place (such as between communities and assessors or scientists and policy-makers) can also be used as tools for enhancing KE (Fazey et al. 2010; Sheate \& Partidário 2010). Irrespective of whether it is a specific tool, strategic assessment, or participatory and deliberative research, the potential to promote KE depends on a conscious effort to introduce genuine opportunities to facilitate KE in initial process designs (Chambers 1997; Fazey et al. 2010; Sheate \& Partidário 2010). There are therefore a plethora of as yet unanswered questions about the different tools and techniques related to KE (Questions 68-73, Table 4).

\section{Changes in how $K E$ is understood and implemented}

Emphasis and implementation of linkages and knowledge sharing have been changing in environmental management over the last three decades in three key ways. First, knowledge sharing has traditionally been viewed as a one way process of transfer from researchers to practitioners (Schneider et al. 2009). Increasingly, however, there has been greater 
recognition of the value of different forms of knowledge, from indigenous to local, from science to practice, and the need to engage with a whole range of groups to make decisions and achieve desired outcomes (Cash et al. 2003; Aswani \& Hamilton 2004; Pretty 2011). Knowledge sharing is now increasingly seen as multidirectional, with learning opportunities and insights to be gained for all involved through a process of the sharing and coproduction of knowledge (Armitage et al. 2008; Schneider et al. 2009).

Second, researchers, policy-makers, agencies, practitioners, non-governmental organizations (NGOs), businesses and communities have traditionally been seen as disparate groups with distinct cultures, priorities and needs (Schneider $e t$ al. 2009; Francis \& Goodman 2011). This has made the sharing and translation of knowledge and innovation difficult. Yet, it is now much more common to have scientists working on policy, communities leading practice, practitioners and communities contributing to research, knowledge brokers and organizations that cross traditional boundaries facilitating the sharing of knowledge, and so on (Hahn et al. 2006; Lukman et al. 2009; Johnson 2011; Sheikheldin et al. 2011). Differences and barriers remain (Choi et al. 2005; Francis \& Goodman 2011), but the boundaries across groups and between science and society are becoming less distinct.

Third, even though environmental management has for some time been conceived as interdisciplinary, the field was initially dominated by the natural sciences (Soule 1985). The natural sciences still play a major role (Fazey et al. 2005b), but there has been a shift towards viewing environmental management as a process involving complex and dynamic relationships between people and the environment (Aswani \& Hamilton 2004; Bienabe \& Hearne 2006; Ballinger \& Stojanovic 2010; Blackstock et al. 2011). This has led to recognition of the need to include and integrate knowledge and perspectives from a much wider range of disciplines (Evely et al. 2008; Pretty 2011).

These trends have been occurring in a context where the relationship between science and society is also changing (Beck 1992; Funtowicz \& Ravetz 1993; Nowotny et al. 2001). Greater recognition of the inherent uncertainties and complexities of scientific knowledge (Gallopin et al. 2001), increasing demand for research to inform solutions to rapid global change (Funtowicz \& Ravetz 1993), and increasing moves towards participatory and deliberative forms of governance (Reed 2008) are being influenced by, and are themselves influencing, changes in applied research fields (Bradshaw \& Borchers 2000; Francis \& Goodman 2011). Some of the trends in knowledge production and sharing in environmental management are also being directly driven by new funding mechanisms and incentives (UNESCO 1998); , such as in the UK, where there is growing emphasis on directed research programmes, projects being required to identify potential beneficiaries, and for researchers to develop strategies for KE (Shove \& Rip 2000; Research Councils UK 2009; Phillipson et al. 2012). Together, these trends and changes raise a wide range of research questions, such as implications for the way $\mathrm{KE}$ is delivered and conceptualized, and the kinds of incentives needed to help researchers to increase involvement in $\mathrm{KE}$ (Questions 74-80, Table 4).

\section{An integrated research agenda on KE}

Further analysis of the 80 research questions led to the identification of 45 subtopics within four themes about stages of the KE process and two broader generic themes (Fig. 1). These themes, subtopics and questions provide strategic focus for targeting funds and effort in an integrated fashion. The themes of the integrated research agenda include research questions on: setting objectives and goals; how participants could or should be engaged in KE; how KE should be implemented or what happens during KE (namely the process of KE); and evaluating KE. The two broader themes were understanding the theory of $\mathrm{KE}$, and how societal changes (for example the relationship of society with science) affect and influence how KE is understood and implemented (Fig. 1).

\section{DISCUSSION}

This paper provides the first and, so far, the most comprehensive framework for guiding research on KE. The process of expert elicitation and further review provided a comprehensive overview of the breadth of topics and research areas and questions (Table 4) and an integrated research agenda for improving understanding of KE (Fig. 1). The list of topics and questions are not definitive, as other experts are likely to identify additional questions, while the final summary of reviewed sections was necessarily selective. For example, if the participants had consisted predominantly of ecologists or environmental managers, issues of interacting geographical scales (such as the problems of transferring knowledge across different spatial scales based on limited sitespecific or experiment-specific information) are likely to have been at the forefront of their concerns. In our workshop, the participants did raise the importance of defining outcomes at both individual, group and more collective levels, hierarchies of expertise, and issues around temporal scale and especially in the context of knowledge (for example, see questions 10,13,14, 17 and 19), but did not focus specifically on scale in the sense ecologists might have. Nevertheless, despite some potential limitations of our approach, which are inevitably a reflection of the participants involved, we provide a robust analysis of the current knowledge of academic experts focused on studying and practising $\mathrm{KE}$, who also have an interest in how the information they produce is exchanged and used.

Overall, the agenda highlights five main issues. First, there is a wide range of questions relating to $\mathrm{KE}$ that require further research. Second, 44 of the 80 research questions were related to understanding the 'process' of KE. Given that the majority of questions related to this theme, further research should be devoted to improving understanding of the process of KE. Third, particular emphasis is required on how KE should or 


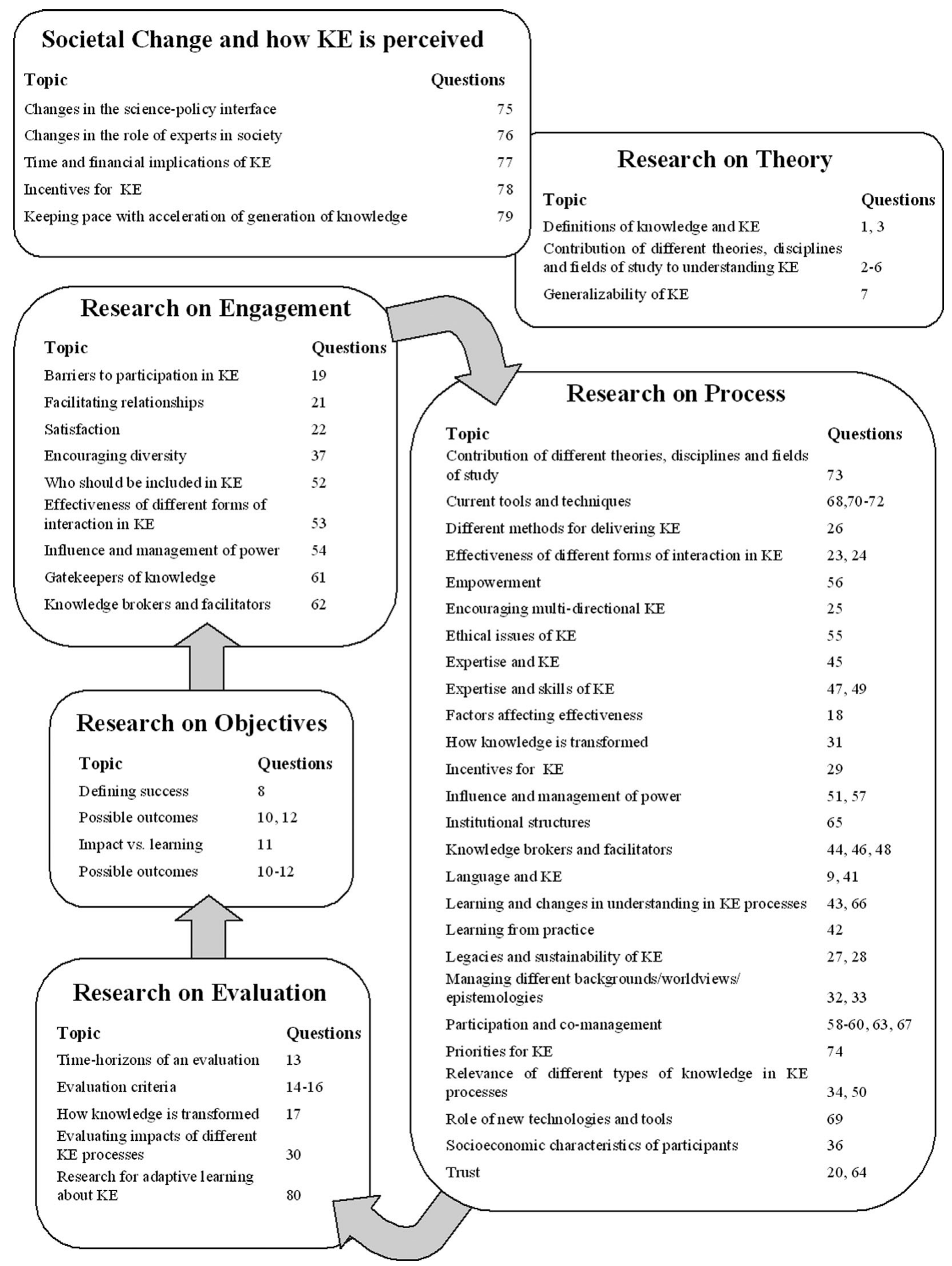

Figure 1 Key research areas and questions that require additional attention identified by experts under four themes relating to the KE cycle and broader, generic themes relating to understanding the theory of $\mathrm{KE}$ and how societal changes (such as the relationship of society with science) affect and influence how KE is understood and implemented. Each research of the research questions (see Table 4) is only identified once in the figure. 
could be evaluated. This is not only because evaluation of $\mathrm{KE}$ projects and programmes is currently lacking, but also because developing effective evaluation methodologies and implementing them is key to addressing many of the other research questions. Fourth, many of the research questions cannot easily be addressed without addressing others. For example, to address questions about evaluating $\mathrm{KE}$, some of the questions about identifying objectives and how $\mathrm{KE}$ is conceptualized also need to be considered. This highlights the need for those setting research agendas to simultaneously encourage in-depth and robust investigations of $\mathrm{KE}$ in ways that also ensure work is integrated across research themes. Finally, the wide range of questions and the strong dependence of answers to one question on how other questions are answered means that prioritization of questions is difficult and inappropriate. This again highlights the importance of an integrated and interdisciplinary approach to enhancing understanding of $\mathrm{KE}$.

Implementing the integrated research agenda on $\mathrm{KE}$ also needs to consider many of the other key messages that emerge from material reviewed in this paper. $\mathrm{KE}$ is an interdisciplinary applied field involving a multitude of topics that requires input from researchers, practitioners and beneficiaries and consideration of diverse epistemological and ontological perspectives and needs. Addressing research gaps will not be a linear process, and research and practice in $\mathrm{KE}$ need to develop alongside one another in an iterative manner. Incentives are therefore required to help facilitate research that establishes and uses appropriate action research methodologies, that makes best use of the learning opportunities provided by existing KE projects, and embeds evaluation as a normal part of $\mathrm{KE}$ research and practice. By doing so, an adaptive learning approach where continual learning about $\mathrm{KE}$ will be encouraged.

Understanding about $\mathrm{KE}$ can also be enhanced by exchange of the findings and outcomes of the research. That is, state of the art knowledge of $\mathrm{KE}$ needs to be used to enhance effective exchange of knowledge about KE. This paper provides a vast array of ideas and considerations needed for effective KE. Importantly, KE is a complex and dynamic process and it is naive to view knowledge as something that can be extracted and passed on in inert form. This view leads to simplistic approaches of 'dissemination' and 'communication' that do not take into account the complex ways in which individual experience and values influence the way people engage with knowledge and ideas, the role of other people, cultures and society in the process, and the wide contextual factors that influence knowledge generation and sharing. Thus, like researchers in other fields, those wanting to exchange knowledge about $\mathrm{KE}$ need to employ principles of best practice that take into account some of these complexities (see Sustainable Learning et al. 2011). Greater consideration of these complexities will be facilitated by emerging networks of those interested in doing and learning about KE (see http://sustainable-learning.org/ and http://learningforsustainability.net/).

\section{CONCLUSION}

Many research areas in environmental management demand greater attention. This paper, however, highlights the importance of $\mathrm{KE}$ as a research area in its own right. Understanding and implementing KE underpins much of what environmental researchers and practitioners aim to achieve. As the relationship between science and society continues to change, demands for researchers to consider KE more deeply will increase. Research projects in environmental management will also increasingly be required to deliver engagement with stakeholders, consider the diversity of understandings and perspectives involved, encourage cogeneration of knowledge, and bridge science, decisions, policy and practice. The integrative research agenda outlined in this paper provides the focus needed for funders and researchers to direct research towards enhancing understanding of KE. It also highlights the need for environmental researchers and practitioners to engage more deeply with, and to think more explicitly and carefully about, the design of $\mathrm{KE}$ projects and programmes in ways that acknowledge the complexities of $\mathrm{KE}$ processes.

\section{ACKNOWLEDGEMENTS}

This work was conducted as part of the project Transforming Knowledge for Sustainable Uplands funded though the Rural Economy and Land Use (RELU) which is a collaboration between the UK's Economic and Social Research Council (ESRC), the Biotechnology and Biological Sciences Research Council (BBSRC) and the Natural Environment Research Council (NERC). P. White is also grateful to the NERC BESS programme for funding. We thank two anonymous reviewers who provided insightful comments that improved the manuscript.

\section{References}

Adams, W., Hulme, D. \& Murphree, M. (2001) Changing Narratives, Policies and Practices in African Conservation'. The Promise and Performance of Community Conservation. Oxford, UK: James Currey.

Alcorn, J.B. (1993) Indigenous peoples and conservation. Conservation Biology 7(2): 424-426.

Allan, C. \& Stankey, G. (2009) Adaptive Environmental Management: A Practitioner's Guide. Dordrecht, the Netherlands: Springer/CSIRO Publishing.

Argote, L., McEvily, B. \& Reagans, R. (2003) Managing knowledge in organizations: an integrative framework and review of emerging themes. Management Science 49(4): 571-582.

Armitage, D., Marschke, M. \& Plummer, R. (2008) Adaptive comanagement and the paradox of learning. Global Environmental Change. Human and Policy Dimensions 18(1): 86-98.

Armitage, D., Berkes, F., Dale, A., Kocho-Schellenberg, E. \& Patton, E. (2011) Co-management and the co-production of knowledge: learning to adapt in Canada's Arctic. Global Environmental Change. Human and Policy Dimensions 21(3): 995-1004. 
Aswani, S. \& Hamilton, R.J. (2004) Integrating indigenous ecological knowledge and customary sea tenure with marine and social science for conservation of bumphead parrotfish (Bolbometopon muricatum) in the Roviana Lagoon, Solomon Islands. Environmental Conservation. 31(1): 69-83.

Ballinger, R. \& Stojanovic, T. (2010) Policy development and the estuary environment: a Severn Estuary case study. Marine Pollution Bulletin 61(1-3): 132-145.

Barnes, B. (1983) Social-life as bootstrapped induction. Sociology 17: 524-545.

Barnes, B. (1988) The Nature of Power. Cambridge, UK: Polity Press. Barnes, B., Bloor, D. \& Henry, J. (1996) Scientific Knomledge: a Sociological Analysis. London, UK: Athlone Press.

Basso, B. (1996) Wisdom Sits in Places: Landscape and Language Among the Western Apache. Albuquerque, New Mexico, USA: University of New Mexico Press.

Beck, U. (1992) Risk Society: Tomards a Nem Modernity. London, UK: Sage.

Bennett, J. \& Bennett, L. (2003) A review of factors that influence the diffusion of innovation when structuring a faculty training program. Internet and Higher Education 6: 53-63.

Berkes, F., Colding, J. \& Folke, C. (2003) Navigating SocialEcological Systems: Building Resilience for Complexity and Change. Cambridge, UK: Cambridge University Press.

Best, A. \& Holmes, B. (2010) Systems thinking, knowledge and action: towards better models and methods. Evidence and Policy 6(2): 145-159.

Bienabe, E. \& Hearne, R.R. (2006) Public preferences for biodiversity conservation and scenic beauty within a framework of environmental services payments. Forest Policy and Economics 9(4): 335-348.

Bierly, P.E., Kessler, E.H. \& Christensen, E.W. (2000) Organizational learning, knowledge and wisdom. Fournal of Organizational Change Management 13(6): 595-618.

Blackstock, K.L., Ingram, J., Burton, R., Brown, K.M. \& Slee, B. (2011) Understanding and influencing behaviour change by farmers to improve water quality. Science of the Total Environment 408(23): 5631-5638.

Blaikie, P., Brown, K., Stocking, M., Tang, L., Dixon, P. \& Sillitoe, P. (1997) Knowledge in action: local knowledge as a development resource and barriers to its incorporation in natural resource research and development. Agricultural Systems 55(2): 217237.

Bloom, B., Englehart, M., Furst, E., Hill, W. \& Krathwohl, D. (1956) Taxonomy of Educational Objectives: The Classification of Educational Goals. Handbook I: Cognitive Domain. New York, NY, USA: Longmans.

Bloor, D. (1991) Knomledge and Social Imagery. Chicago, USA and London, UK: University of Chicago Press.

Bradshaw, G.A. \& Borchers, J.G. (2000) Uncertainty as information: narrowing the science-policy gap. Conservation Ecology 4(1): art 7 [www document]. URL http://www. ecologyandsociety.org/vol4/iss1/art7/

Bransford, J. D., Brown, A.L. \& Cocking, R.R. (2000) How People Learn: Brain, Mind, Experience, and School. Washington, DC, USA: National Academy Press.

Brockington, D. (2002) Fortress Conservation: the Preservation of the Mkomazi Game Reserve, Tanzania. London, UK: The International African Institute in association with James Currey, Oxford; Mkuki Na Nyota, Dar es Salaam; Indiana University Press, Bloomington \& Indianapolis.
Brugnach, M. \& Ingram, H. (2012) Ambiguity: the challenge of knowing and deciding together. Environmental Science and Policy 15(1): 60-71.

Bucciarelli, L.L. (1988) An ethnographic perspective on engineering design. Design Studies 9(3): 159-168.

Campbell, L.M. \& Vainio-Mattila, A. (2003) Participatory development and community-based conservation: opportunities missed for lessons learned? Human Ecology 31(3): 417437.

Cash, D.W., Clark, W.C., Alcock, F., Dickson, N.M., Eckley, N., Guston, D.H., Jäger, J. \& Mitchell, R.B. (2003) Knowledge systems for sustainable development. Proceedings of the National Academy of Sciences USA 100(14): 8086-8091.

Chambers, R. (1997) Whose Reality Counts?: Putting the First Last. London, UK: ITDG Publishing.

Checkland, P.B. (1998) Systems Thinking, Systems Practice. Chichester, UK: John Wiley \& Sons Ltd.

Choi, B.C.K., Pang, T., Lin, V., Puska, P., Sherman, G., Goddard, M., Ackland, M.J., Sainsbury, P., Stachenko, S., Morrison, H. \& Clottey, C. (2005) Can scientists and policy makers work together? Journal of Epidemiology and Community Health 59(8): 632637.

Cortazzi, M. \& Jin, L. (1999) Bridges to learning: metaphors of teaching, learning and language. In: Researching and Appling Metaphor, ed. L. Cameron \& G. Low, Cambridge, UK: Cambridge University Press.

Cortazzi, M. \& Jin, L. (2002) Cultures of learning: the social construction of educational identities. In: Discourses in Search of Members, in Honor of Ron Scollon., ed. D.C.S. Li, pp. 49-78. Lanham, USA: University Press of America.

Cortazzi, M., Pilcher, N. \& Jin, L. (2011) Language choices and 'blind shadows': investigating interviews with Chinese participants. Qualitative Research 11(5): 505-535.

Cranford, M. \& Mourato, S. (2011) Community conservation and a two-stage approach to payments for ecosystem services. Ecological Economics 71: 89-98.

Cribb, J. \& Hartomom, T. S. (2002) Sharing Knomledge: A Guide to Effective Science Communication. Collingwood, Australia: CSIRO Publishing.

Cundill, G.N.R., Fabricius, C. \& Marti, N. (2005) Foghorns to the future: using knowledge and transdisciplinarity to navigate complex systems. Ecology and Society 10(2): art 8 [www document]. URL www.ecologyandsociety.org/vol10/iss2/art8/ ES-2005-1444.pdf

Davies, H., Nutley, S. \& Walter, I. (2008) Why 'knowledge transfer' is misconceived for applied social research. Fournal of Health Services Research and Policy 13(3): 188-190.

Dobbins, M., Hanna, S.E., Ciliska, D., Manske, S., Cameron, R., Mercer, S.L., O’Mara, L., DeCorby, K. \& Robeson, P. (2009) A randomized controlled trial evaluating the impact of knowledge translation and exchange strategies. Implementation Science 4(1): 61 .

Duchelle, A.E., Biedenweg, K., Lucas, C., Virapongse, A., Radachowsky, J., Wojcik, D.J., Londres, M., Bartels, W.L., Alvira, D. \& Kainer, K.A. (2009) Graduate students and knowledge exchange with local stakeholders: possibilities and preparation. Biotropica 41(5): 578-585.

Dwivedi, Y.K., Venkitachalam, K., Sharif, A.M., Al-Karaghouli, W. \& Weerakkody, V. (2011) Research trends in knowledge management: analyzing the past and predicting the future. Information Systems Management 28(1): 43-56. 
Entwistle, N. (2001) Styles of learning and approaches to studying in higher education. Kybernetes 30(5-6): 593-602.

Entwistle, N. \& Smith, C. (2002) Personal understanding and target understanding: mapping influences on the outcomes of learning. British Fournal of Educational Psychology 72: 321-342.

European Communities (2006) Evaluation methods for the European Union's External Assistance. Volume 1: Methodological Bases for Evaluation. Luxemburg: European Commission [www document]. URL http://ec.europa.eu/europeaid/evaluation/ methodology/examples/guide1_en.pdf

Evely, A., Fazey, I., Reed, A.E. \& Stringer, L. (2012) Designing knowledge exchange for resilience: how people view and construct knowledge matters. Sustainable Learning Working Paper Series no. 2 [www document]. URL http://sustainablelearning.org/wp-content/uploads/2012/01/Evely-et-al-2012Sustainable-Learning-Working-Paper-Series-No.-2.pdf

Evely, A.C., Fazey, I., Pinard, M. \& Lambin, X. (2008) The influence of philosophical perspectives in integrative research: a conservation case study in the Cairngorms National Park. Ecology and Society 13(2): art 52 [www document]. URL http://www.ecologyandsociety.org/vol13/iss2/art52/

Evely, A.C., Pinard, M., Reed, M. S. \& Fazey, I. (2011) High levels of participation in conservation projects enhance learning. Conservation Letters 4(2): 116-126.

Fazey, I. (2010) Resilience and higher order thinking. Ecology and Society 15(3): art 9 [www document]. URL http://www. ecologyandsociety.org/vol15/iss3/art9/

Fazey, I., Fazey, J.A. \& Fazey, D.M.A. (2005a) Learning more effectively from experience. Ecology and Society 10(2): Art 4 [www document]. URL http://www.ecologyandsociety. org/vol10/iss2/art4/

Fazey, I., Fischer, J. \& Lindenmayer, D.B. (2005b) What do conservation biologists publish? Biological Conservation 124(1): 63-73.

Fazey, I., Fazey, J.A., Salisbury, J.G., Lindenmayer, D.B. \& Dovers, S. (2006) The nature and role of experiential knowledge for environmental conservation. Environmental Conservation 33(1): 110.

Fazey, I., Kesby, M., Evely, A., Latham, I., Wagatora, D., Hagasua, J.E., Reed, M.S. \& Christie, M. (2010) A three-tiered approach to participatory vulnerability assessment in the Solomon Islands. Global Environmental Change. Human and Policy Dimensions 20(4): 713-728.

Fetterman, D. \& Wandersman, A. (2005) Empomerment Evaluation: Principles in Practice. New York, NY, USA and London, UK: Guilford Press.

Fischer, J., Dyball, R., Fazey, I., Dovers, S., Ehrlich, P.R., Gross, C., Brulle, R.J., Christenson, C. \& Borden, R.J. (2012) Human behaviour and sustainability. Frontiers in Ecology and the Environment 10: 153-160.

Foucault, M. \& Gordon, C. (1980) Power/Knomledge: Selected Interviems and Other Writings, 1972/1977. Brighton, UK: Harvester Press.

Francis, R.A. \& Goodman, M.K. (2011) Post-normal science and the art of nature conservation. Fournal for Nature Conservation 18(2): $89-105$.

Funtowicz, S.O. \& Ravetz, J.R. (1993) Science for the post-normal age. Futures 25(7): 739-755.

Gallopin, G.C., Funtowicz, S., O'Connor, M. \& Ravetz, J. (2001) Science for the twenty-first century: from social contract to the scientific core. International Social Science Fournal 53(2): 219.
Garnett, S.T., Crowley, G.M., Hunter-Xenie, H., Kozanayi, W., Sithole, B., Palmer, C., Southgate, R. \& Zander, K.K. (2009) Transformative knowledge transfer through empowering and paying community researchers. Biotropica 41(5): 571577.

Gaventa, J. (2004) Towards participatory governance: assessing the transformative possibilities. In: Participation: From Tyranny to Transformation?, ed. S. Hickey \& G. Mohan, pp. 25-41. London, UK: Zed Books.

Gerrish, K., McDonnell, A., Nolan, M., Guillaume, L., Kirshbaum, M. \& Tod, A. (2011) The role of advanced practice nurses in knowledge brokering as a means of promoting evidence-based practice among clinical nurses. Fournal of Advanced Nursing 67(9): 2004-2014.

Glass, J.H., Scott, A.J. \& Price, M.F. (2012) The power of the process: co-producing a sustainability assessment toolkit for upland estate management in Scotland. Land Use Policy 30(1): 254-265.

Gould, R.V. \& Fernandez, R.M. (1989) Structures of mediation: a formal approach to brokerage in transaction networks. Sociological Methodology 19: 89-126.

Graham, I D., Logan, J., Harrison, M.B., Straus, S.E., Tetroe, J., Caswell, W. \& Robinson, N. (2006) Lost in knowledge translation: time for a map? The Fournal of Continuing Education in the Health Professions 26(1): 13-24.

Hage, M., Leroy, P. \& Petersen, A.C. (2010) Stakeholder participation in environmental knowledge production. Futures 42(3): 254-264.

Hahn, T., Olsson, P., Folke, C. \& Johansson, K. (2006) Trustbuilding, knowledge generation and organizational innovations: the role of a bridging organization for adaptive comanagement of a wetland landscape around Kristianstad, Sweden. Human Ecology 34(4): 573-592.

Hickey, S. \& Mohan, G. (2004) Participation, from Tyranny to Transformation?: Exploring New Approaches to Participation in Development. London, UK and New York, NY, USA: ZED Books.

Hofer, B.K. (2000) Dimensionality and disciplinary differences in personal epistemology. Contemporary Educational Psychology 25(4): 378-405.

Hoffman, P. (1998) The Man Who Loved Only Numbers: The Story of Paul Erdös and the Search for Mathematical Truth. New York, NY, USA: Hyperion.

Hogan, C. (2002) Understanding Facilitation. London, UK: Kogan Page Ltd.

Ingram, H. \& Stern, P. (2007) Research and Networks for Decision Support in the NOAA Sectoral Applications Research Program. Washington, DC, USA: National Academy Press.

Irvin, R.A. \& Stansbury, J. (2004) Citizen participation in decision making: is it worth the effort? Public Administration Reviem 64(1): $55-65$.

Johnson, F.A. (2011) Learning and adaptation in the management of waterfowl harvests. Fournal of Environmental Management 92(5): $1385-1394$.

Kapoor, I. (2002) The devil's in the theory: a critical assessment of Robert Chambers' work on participatory development. Third World Quarterly 23(1): 101-117.

Kenter, J.O., Hyde, T., Christie, M. \& Fazey, I. (2011) The importance of deliberation in valuing ecosystem services in developing countries. Evidence from the Solomon Islands. Global Environmental Change. Human and Policy Dimensions 21(2): 505521. 
Klerkx, L. \& Leeuwis, C. (2008) Matching demand and supply in the agricultural knowledge infrastructure: experiences with innovation intermediaries. Food Policy 33(3): 260276.

Kruijsen, J.H.J. (1999) Photovoltaic Technology Diffusion. Eburon, Delft, the Netherlands: Contact \& Interact.

Lakoff, G. \& Johnson, M. (1980) Metaphors We Live By. Chicago, IL, USA: University of Chicago Press.

Lane, J.P. \& Rogers, J.D. (2011) Engaging national organizations for knowledge translation: comparative case studies in knowledge value mapping. Implementation Science 6: 106.

Lansing, J.S. (1991) Priests and Programmers: Technologies of Power in the Engineered Landscape of Bali. Princeton, USA: Princeton University Press.

Lawler, J.J., Aukema, J.E., Grant, J.B., Halpern, B.S., Kareiva, P., Nelson, C.R., Ohleth, K., Olden, J.D., Schlaepfer, M.A., Silliman, B.R. \& Zaradic, P. (2006) Conservation science: a 20year report card. Frontiers in Ecology and the Environment 4(9): 473480.

Laycock, H., Moran, D., Smart, J., Raffaelli, D. \& White, P. (2009) Evaluating the cost-effectiveness of conservation: the UK biodiversity action plan. Biological Conservation 142: 3120 3127.

Laycock, H.F., Moran, D., Smart, J.C.R., Raffaelli, D. \& White, P.C.L. (2011) Evaluating the effectiveness and efficiency of biodiversity conservation spending. Ecological Economics 70: 1789 1796.

Lee, K.N. (1999) Appraising adaptive management. Conservation Ecology 3(2): 3.

Lukman, R., Krajnc, D. \& Glavič, P. (2009) Fostering collaboration between universities regarding regional sustainability initiatives: the University of Maribor. Fournal of Cleaner Production 17(12): $1143-1153$.

Marshall, G.R. (2008) Testing, subsidiarity, and community-based environmental governance beyond the local level. International Fournal of the Commons 2(1): 75-97.

Meyer, M. (2011) The rise of the knowledge broker. Science Communication 32(1): 118-127.

Nonaka, I., Toyama, R. \& Konno, N. (2000) SECI, ba and leadership: a unified model of dynamic knowledge creation. Long Range Planning 33(1): 5-34.

Nowotny, H., Scott, P. \& Gibbons, M. (2001) Re-Thinking Science: Knomledge and the Public in an Age of Uncertainty. Cambridge, UK: Polity Press.

Nutley, S., Morton, S., Jung, T. \& Boaz, A. (2010) Evidence and policy in six European countries: diverse approaches and common challenges. Evidence and Policy 6(2): 131-144.

Parfitt, T. (2004) The ambiguity of participation: a qualified defence of participatory development. Third World Quarterly 25(3): 537556.

Partidário, M.R. \& Sheate, W.R. (2013) Knowledge brokerage: potential for increased capacities and shared power in impact assessment. Environmental Impact Assessment Reviem (in press) [www document].URL http://dx.doi.org/10.1016/j.eiar.2012.02.002

Phillipson, J., Lowe, P., Proctor, A. \& Ruto, E. (2012) Stakeholder engagement and knowledge exchange in environmental research. Fournal of Environmental Management 95: 56-65.

Prager, K., Reed, M. \& Scott, A. (2012) Encouraging collaboration for the provision of ecosystem services at a landscape scale: rethinking agri-environmental payments. Land Use Policy 29(1): 244-249.
Pretty, J. (2011) Interdisciplinary progress in approaches to address social-ecological and ecocultural systems. Environmental Conservation 38(2): 127-139.

Proctor, A., Phillipson, J., Lowe, P. \& Donaldson, A. (2011) Field advisors as agents of knowledge exchange. Rural Economy and Land Use Programme Policy and Practice Note, School of Agriculture, Food and Rural Development, University of Newcastle, Newcastle Upon Tyne, UK.

Pullin, A.S. \& Knight, T.M. (2001) Effectiveness in conservation practice: pointers from medicine and public health. Conservation Biology 15(1): 50-54.

Raymond, C.M., Fazey, I., Reed, M.S., Stringer, L.C., Robinson, G.M. \& Evely, A.C. (2010) Integrating local and scientific knowledge for environmental management. Fournal of Environmental Management 91(8): 1766-1777.

Research Councils UK (2009) Excellence with impact: framework for the future. Report. Research Councils UK, Swindon, UK.

Reed, M.S. (2008) Stakeholder participation for environmental management: a literature review. Biological Conservation 141(10): 2417-2431.

Reed, M.S., Graves, A., Dandy, N., Posthumus, H., Hubacek, K., Morris, J., Prell, C., Quinn, C. H. \& Stringer, L.C. (2009) Who's in and why? A typology of stakeholder analysis methods for natural resource management. Fournal of Environmental Management 90(5): 1933-1949.

Reiche, B.S., Harzing, A.-W. \& Kraimer, M.L. (2009) The role of international assignees' social capital in creating inter-unit intellectual capital: a cross-level model. Fournal of International Business Studies 40(3): 509-526.

Reid, K.A., Williams, K.J.H. \& Paine, M.S. (2011) Hybrid knowledge: place, practice, and knowing in a volunteer ecological restoration project. Ecology and Society 16(3): art 19 [www document]. URL http://www.ecologyandsociety.org/ vol16/iss3/art19/ES-2011-4234.pdf

Rogers, E.M. (1995) Diffusion of Innovations. New York, NY, USA: The Free Press.

Rowe, G. \& Frewer, L.J. (2004) Evaluating public-participation exercises: a research agenda. Science Technology and Human Values 29(4): 512-557.

Salafsky, N., Margoluis, R., Redford, K.H. \& Robinson, J.G. (2002) Improving the practice of conservation: a conceptual framework and research agenda for conservation science. Conservation Biology 16(6): 1469-1479.

Salafsky, N., Cauley, H., Balachander, G., Cordes, B., Parks, J., Margoluis, C., Bhatt, S., Encarnacion, C., Russell, D. \& Margoluis, R. (2001) A systematic test of an enterprise strategy for community-based biodiversity conservation. Conservation Biology 15(6): 1585-1595.

Sanchez, L.E. \& Morrison-Saunders, A. (2011) Learning about knowledge management for improving environmental impact assessment in a government agency: the Western Australian experience. Fournal of Environmental Management 92(9): 22602271.

Schneider, F., Ledermann, T., Rist, S. \& Fry, P. (2009) Social learning processes in Swiss soil protection: the 'From Farmer To Farmer' project. Human Ecology 37(4): 475-489.

Scollon, R. \& Scollon, S.W. (1981) Narrative, Literacy and Face in Interethnic Communication. Norwood, NJ, USA: Ablex Publishing. Scollon, R. \& Scollon, S.W. (2001) Intercultural Communication, a Discourse Approach. Oxford, UK: Blackwell Publishers. 
Sheate, W.R. \& Partidário, M.R. (2010) Strategic approaches and assessment techniques: potential for knowledge brokerage towards sustainability. Environmental Impact Assessment Reviem 30(4): 278288.

Sheikheldin, G., Krantzberg, G. \& Schaefer, K. (2011) Scienceseeking behaviour of conservation authorities in Ontario. Environmental Management 45(5): 912-921.

Shove, E. \& Rip, A. (2000) Users and unicorns: a discussion of mythical beasts in interactive science. Science and Public Policy 27(3): 175-182.

Shufflebeam, D.L. \& Shinkfield, A.J. (2007) Evaluation Theory, Models and Applications. San Francisco, CA, USA: Jossey Bass.

Sorensen, C.G., Fountas, S., Nash, E., Pesonen, L., Bochtis, D., Pedersen, S.M., Basso, B. \& Blackmore, S.B. (2010) Conceptual model of a future farm management information system. Computers and Electronics in Agriculture 72(1): 37-47.

Soule, M.E. (1985) What is conservation biology. Bioscience 35(11): 727-734.

Steffen, W., Sanderson, A., Tyson, P.D., Jäger, J., Matson, P.A., Moore III, B., Oldfield, F., Richardson, K., Schellnhuber, H.-J., Turner II, B.L. \& Wasson, R.J. (2004) Global Change and the Earth System: A Planet Under Pressure. Berlin, Germany: Springer.

Sustainable Learning, Natural Environment Research Council \& Living With Environmental Change (2011) Guidelines to knowledge exchange: draft document [www document]. URL http://sustainable-learning.org/wp-content/uploads/2011/12/ Integrated-Guidelines-vs1.pdf

Ting-Toomey, S. (1999) Communicating Across Cultures. New York, NY, USA: The Guilford Press.

Tress, G., Tress, B. \& Fry, G. (2005) Clarifying integrative research concepts in landscape ecology. Landscape Ecology 20(4): 479-493.
Trevitt, C. (2008) Learning in academia is more than academic learning: action research in academic practice for and with medical academics. Educational Action Research 16(4): 495-515.

UNESCO (1998) The role of science and technology in society and governance. Toward a new contract between science and society. Executive summary of the report of the North American Meeting held in advance of the World Conference on Science. UNESCO, Budapest, Hungary [www document]. URL http://www.unesco.org/science/wcs/meetings/eur_alberta_98 _e.htm

Valente, T. (1996) Social network tresholds in the diffusion of innovations. Social Networks 18(1): 69-89.

Verbeke, W., Dietz, B. \& Verwaal, E. (2011) Drivers of sales performance: a contemporary meta-analysis. Have salespeople become knowledge brokers? Fournal of the Academy of Marketing Science 39(3): 407-428.

Ward, V.L., House, A.O. \& Hamer, S. (2009) Knowledge brokering: exploring the process of transferring knowledge into action. BMC Health Services Research 9: art 12 [www document]. URL http://www.biomedcentral.com/1472-6963/9/12/

Webler, T., Tuler, S. \& Krueger, R. (2001) What is a good public participation process? Five perspectives from the public. Environmental Management 27(3): 435-450.

Whiteley, J., Ingram, H. \& Perry, R. (2008) Water, Place and Equity. Cambridge, MA, USA: MIT Press.

Williams, G., Veron, R., Corbridge, S. \& Srivastava, M. (2003) Participation and power: poor people's engagement with India's employment assurance scheme. Development and Change 34(1): 163-192.

Zukoski, A. \& Luluquisen, M. (2002) Participatory evaluation. What is it? Why do it? What are the challenges? Community-based Public Health Policy and Practice 5: 1-6. 